\title{
Colorimetría de pellets de eucalipto y residuos de la cafeicultura y sus relaciones con los parámetros de calidad
}

\author{
Colorimetry of pellets produced with eucalyptus and coffee cultivation \\ residues and their relationship to quality standards
}

\author{
Hector Jesus Pegoretti ${ }^{1}$, Marina Donária Chaves $^{2}$, Graziela Baptista Vidaurre ${ }^{3}$, \\ Victor Fassina Brocco ${ }^{3}$, Daniel Pegoretti de Souza ${ }^{4}$ e Thiago De Paula Protásio ${ }^{5}$
}

\begin{abstract}
Resumen
La matriz energética mundial se basa en el uso de combustibles fósiles, principal causa del efecto invernadero, por lo que se buscan fuentes alternativas con potencial para satisfacer las necesidades energéticas actuales con menor impacto ambiental. En este sentido, la peletización de los residuos agroforestales es una alternativa para fines energéticos. A pesar de que Brasil presenta condiciones edafoclomáticas favorables, aun se tiene mucho que perfeccionar. Los principales desafíos limitantes son: el alto costo logístico de transporte, la ausencia de infraestructura adecuada en los puertos y ausencia de equipos con tecnología adecuada para producir pellets con mayor eficiencia. El objetivo de este trabajo fue correlacionar las características colorimétricas de los pellets, obtenidas por el sistema Commission Internationale de léclairage (CIE- $L{ }^{*} a{ }^{*} b$ *), a los valores de cenizas, extractivos y poder calorífico. Se utilizaron tres clones de eucalipto (A, B y C) y tres residuos del procesamiento de la pulpa de café (pergamino, película plateada y cáscara externa), siendo elaboradas seis composiciones. Se han peletizado los residuos $100 \%$ puros y se ha analizado una muestra de pellet comercial nacional (producido con madera de eucalipto). El color de los pellets fue evaluado por el sistema CIE-L * $a$ * $b$ * y se concluyó que altos porcentajes de cenizas producen pellets más oscuros. Los pellets de película plateada (PP) y la casca externa (CE) presentaron una variación total después de la peletización $(\Delta \mathrm{E})$ de 31,14 y 29,34 , respectivamente, indicando que son los más oscuros, y en la escala de luminosidad $(L *)$ están cerca de 30. Esto desfavorece la calidad de los pellets y sus propiedades energéticas, ya que niveles por encima de 32 superan los valores establecidos de cenizas y los pellets no se ajustarían a las normas europeas, imposibilitando así la comercialización en el mercado internacional .
\end{abstract}

Palabras Clave: Energía renovable; Compactación de biomassa; Densificación; Sistema de color

\begin{abstract}
The world's energy matrix relies on the use of fossil fuels, main cause of the greenhouse effect. For such reason, there is a need to find renewable fuel alternatives with the potential to supply current energy demands while reducing the environmental impacts. Therefore, one alternative is the production of pellets using agroforestry residues. Hence, despite having favorable edaphoclimatic conditions, Brazil still has much to learn and improve. The main constraints are: high logistics and transportation costs, maritime ports do not have the necessary conditions and infrastructure, and absence of equipment to produce pellets efficiently. This project's objective is to correlate the pellets' colorimetric characteristics under the Commision Internationale de IÉclairage (CIE-L*a* $b^{*}$ ) to ash and extractives content and heating values. Three eucalypt clones (A, B, and C) and three coffee depulping process' residues (parchment, silver screen, and external bark) were used, and six compositions were created. Residues that were $100 \%$ pure were pelletized and one sample of a domestic commercial pellet (made with eucalypt biomass) was analyzed. The pellets' color was evaluated under the CIE-L*a*b* system and it was concluded that high ash percentages result in darker pellets. The pellets produced with silver screen $\left(P_{P}\right)$ and external bark $\left(C_{E}\right)$ presented a total variation $(\Delta E)$ of 31.14 and 29.34, respectively, after pelletization, resulting darkest than the others, and close to 30 in the luminosity scale $\left(L^{*}\right)$. These values undermine the pellets' quality and energetic properties, as values above 32 would exceed the recommended ash values and the pellets would not adjust to European standards, thus precluding the commercialization in the international market.
\end{abstract}

Keywords: Renewable energy; Biomass compaction; Densification, Color system

\footnotetext{
1. Universidad De Concepcíon - UDC. Concepcíon, Chile. * Autor correspondiente: hectorj.leite@gmail.com

2. Universidade Federal de São João Del Rei - UFSJ. São João Del Rei / MG, Brasil.

3. Universidade Federal do Espírito Santo - UFES. Jerônimo Monteiro / ES, Brasil.

4. State University of New York College of Environmental Science and Forestry - SUNY /ESF. Syracuse / NY, Estados Unidos d América UA.

5. Universidade Federal Rural da Amazônia - UFRA. Parauapebas / PA, Brasil.
}

Sci. For., Piracicaba, v. 47, n. 121, p. 114-124, mar. 2019 DOI: dx.doi.org/10.18671/scifor.v47n121.11 


\section{INTRODUCCIÓN}

La producción de energía más común en el mundo es por medio de la quema de combustibles fósiles, los cuales están catalogados como los más contaminantes ya que emanan dióxido de carbono $\left(\mathrm{CO}_{2}\right)$, principal causante del efecto invernadero, y además otros gases como óxido de nitrógeno $\left(\mathrm{NO}_{\mathrm{x}}\right)$, monóxido de carbono $(\mathrm{CO})$ y metano $\left(\mathrm{CH}_{4}\right)$. La búsqueda por nuevas fuentes de energía está cada vez más en evidencia, ya que el crecimiento de la población mundial viene aumentando y demandando mayores cantidades de energía.

Por esto, la biomasa vegetal es una fuente energética renovable con potencial para suplir necesidades mundiales acerca de las energías (TUMULURU et al., 2011). Dentro de las alternativas de energía renovables se encuentran las plantaciones forestales (PROTÁSIO et al., 2017) y el uso de los residuos agrícolas (SCATOLINO et al., 2018).

El crecimiento de la actividad forestal en Brasil genera cada vez mayores cantidades de madera, lo que significa que también aumenta la cantidad de residuos. En la parte agrícola como es el caso del café, Brasil se ubica como el mayor productor a nivel mundial, y consecuentemente genera cantidades de residuos que pueden ser utilizados en la generación directa de calor (LEITE et al., 2015) o para la producción de pellets (CUBERO-ABARCA et al., 2014; FARIA et al., 2016). En el pasado esos residuos no eran utilizados de una manera eficaz o simplemente no tenían ningún valor comercial, por lo que muchas veces eran quemados o dejados en el área de la cosecha y utilizados como abono orgánico, catalogándose como un latente desperdicio energético (LAÉRCIO et al., 2004).

Esos residuos de madera y agrícolas que son originarios de las industrias pasaron de una condición de almacenamiento o "estorbo" en las fábricas, hacia una interesante fuente adicional de ingresos dentro del proceso industrial (OLIVEIRA, 2015). En los últimos años, la disputa por esos residuos se tornó competitiva ya que están siendo muy utilizados para generar valor agregado, como, por ejemplo, la frabricaión de pellets para generar energía (GARCIA; CARASCHI, J.; VENTORIM, 2017a; 2018), también en la fabricación de briquetas, carbón o chip para alimentaciones de calderas u otros fines energéticos.

La utilización de biomasa vegetal como fuente de energía renovable es promisoria tanto en el escenario actual como futuro. Debido a que es viable económicamente, y por presentar ventajas ambientales como fijación de carbono durante el crecimiento vegetal y bajas emisiones de gases $\mathrm{NO}_{x^{\prime}} \mathrm{SO}_{\mathrm{x}}$ y CO durante la combustión (GARCIA; CARASCHI; VENTORIM, 2017b), también, reduce la dependencia energética de los derivados del petróleo y lo más importante es de origen renovable.

Además, la combustión de pellets reduce las emisiones gaseosas $\left(\mathrm{NO}_{\mathrm{x}^{\prime}} \mathrm{SO}_{\mathrm{x}} \mathrm{y} \mathrm{CO}\right)$ si comparada con los combustibles fósiles, e incluso comparada a la combustión de biomasa no procesada (GARCIA; CARASCHI; VENTORIM, 2017b). Por lo tanto, la utilización de pellets para generación de energía podría considerarse dentro de los parámetros de calidad del aire establecidos por la Resolución $\mathrm{n}^{\circ} 436$ del Consejo Nacional del Medio Ambiente (CONAMA) de Brasil (BRASIL, 2011). Excepto, si el pellet es producido 100\% corteza de pino, ya que este puede sobrepasar los límites de la norma de emisiones de $\mathrm{CO}$, lo que implica que su aprovechamiento podría estar condicionado al uso de un equipo de captura de gases (GARCIA; CARASCHI; VENTORIM, 2017b).

En Brasil, el sector de la biomasa compactada ha sido el modo más eficiente de viabilizar económicamente los residuos, por ser considerada un combustible limpio y atrayente al consumidor para la generación de energía. El abastecimiento es cuestión de logística y organización, ya que Brasil posee condiciones favorables para llegar a ser un gran productor de pellets (GARCIA et al., 2016). A pesar de eso, se necesitan más estudios referentes a los pellets, donde la calidad fisicoquímica de estos debe ser considerada para la comercialización de este tipo de biocombustible. El contenido de cenizas es un excelente parámetro para evaluar la calidad energética de los pellets (SCATOLINO et al., 2018), ya que los minerales reducen el poder calorífico de los pellets y aumenta las corrosiones de las cocinas, estufas y calderas (GARCIA et al., 2013).

$\mathrm{Al}$ respecto, en el estudio de Sgarbossa et al. (2014) también se menciona que los parámetros de calidad estudiados en la producción de los pellets, la evaluación de color y su relación con la calidad de estos no han sido muy estudiados. Ya que este sistema es más utilizado en madera sólida para 
Pegoretti et al. - Colorimetría de pellets de eucalipto y residuos de la

cafeicultura y sus relaciones con los parámetros de calidad

observar el cambio de madera juvenil y adulta, para ver modificaciones por tratamientos térmicos y ver correlaciones entre las variaciones de densidad (ZANUNCIO et al., 2014).

Sin embargo, el sistema CIE-L*a*b* es un método de lectura de color, preciso y objetivo, que proporciona resultados cuantitativos para los parámetros $\mathrm{L}^{*}$ : luminosidad, $\mathrm{a}^{*}$ : matrices del eje rojo - verde y $\mathrm{b}^{*}$ : matrices del eje amarillo - azul. Esta técnica viene siendo aplicada en estudios con madera, donde es utilizado para detectar diferencias más sensibles, permitiendo correlaciones con diversas propiedades de la madera en niveles entre especies y dentro de la misma especie local (MOYA; BERROCAL, 2010).

Además, este sistema de colorimetría es utilizado para madera sólida y sus resultados han sido satisfactorios (AMORIM et al., 2013). Por lo tanto, se está tomando la iniciativa de ser utilizado en los pellets, con el fin de detectar la calidad de sus parámetros, que está efectivamente correlacionada con los valores colorimétricos. La coloración de los pellets afecta directamente en la selección del consumidor debido a la evaluación visual o aspecto, ya que la apariencia juega un papel importante en el producto. Por este motivo, se analizaron las biomasas 100\% puras y en diferentes combinaciones o mezclas.

En ese sentido, el contenido de cenizas es un excelente índice de calidad de los pellets, cuando es utilizado para un fin energético (SCATOLINO et al., 2018), por lo tanto, métodos indirectos que determinan este parámetro son fundamentales. De este modo el estudio de colorimetría en los pellets puede ayudar a clasificar la calidad de estos en lo que se refiere a las características energéticas.

La hipótesis de este estudio es observar si el sistema CIE-L*a*b* ayuda a verificar la calidad de los pellets a través de los padrones colorimétricos respecto al contenido de cenizas y extractivos y poder calorífico. Por lo tanto, este trabajo tiene como objetivos evaluar la influencia de los extractivos, el contenido de cenizas y los valores energéticos, parámetros de calidad de los pellets, por medio de los padrones colorimétricos CIE-L*a*b*. También determinar las características químicas y físicas de los pellets producidos por residuos del procesamiento de granos de café y madera de eucalipto.

\section{METODOLOGÍA}

La madera (biomasa forestal) utilizada en este estudio fue proveniente de tres clones híbridos de Eucalyptus grandis $x$ Eucaliptus urophylla con 6,5 años, provenientes de plantíos localizados en Nova Viçosa, estado de Bahía (coordenadas $1717^{\circ} 53^{\prime} 44^{\prime \prime}$ latitud sur y $39^{\circ} 34^{\prime} 2^{\prime \prime}$ longitud oeste). Además, fueron utilizados tres residuos del procesamiento del café (biomasa agroindustrial), siendo estos pergamino, película plateada y casca externa, provenientes del distrito de Oriente, que pertenece al municipio de Jerônimo Monteiro (coordenadas $20^{\circ} 47^{\prime} 25^{\prime \prime}$ latitud sur e $41^{\circ} 23^{\prime} 48^{\prime \prime}$ longitud oeste), Espírito Santo.

En virtud de las características de la peletizadora, no fue posible peletizar la biomasa con 100\% de madera de Eucalyptus (clones), ya que el equipo era apropiado para maderas menos densas, como la madera de Pinus. Por lo tanto, fue utilizada una muestra compuesta, es decir, una mezcla de los discos retirados de cada una de las cinco posiciones longitudinales del árbol: 0, 25, 50, 75 y 100\% de la altura comercial, considerada hasta $8 \mathrm{~cm}$ de diámetro, así como también un disco de la región del diámetro a la altura del pecho ( $\mathrm{DAP}=1,30 \mathrm{~m}$ del suelo). Para cada uno de los clones el material fue triturado y homogeneizado para determinar las propiedades y la producción de los pellets.

Las diferentes composiciones de la biomasa forestal con los residuos del despulpado del café fueron obtenidas, evaluadas y utilizadas para la producción de los pellets (Tabla 1). La base de las composiciones fue eucalipto y pergamino debido a la disponibilidad del material y por la facilidad que tiene el pergamino de ser peletizado.

\section{CARACTERIZACIÓN DE LA MADERA DE EUCALIPTO}

La densidad básica fue determinada a través de cuñas opuestas de acuerdo con las normas brasileñas - NBR 6230 y NBR 11941 de la Associação Brasileira de Normas Técnicas - ABNT (1985; 2003).

Las cuñas secas fueron pesadas y se determinó la densidad básica al dividir la masa seca por el volumen saturado de cada muestra. Luego, para obtener la densidad básica de cada posición fue calculada la densidad básica ponderada, empleando el volumen de las toras de las secciones obtenidas por la ecuación 1. 
Tabla 1. Composición de las biomasas para la producción de los pellets

Tabela 1. Composição das biomassas para produção dos pellets

\begin{tabular}{|c|c|c|c|c|c|}
\hline Identificación & Clone & Eucalyptus (\%) & Pergamino (\%) & Película Plateada (\%) & Casca Externa (\%) \\
\hline$E_{A} P P_{P}$ & $A$ & 40 & 30 & 30 & - \\
\hline$E_{B} P P_{P}$ & B & 40 & 30 & 30 & - \\
\hline$E_{c} P P_{P}$ & C & 40 & 30 & 30 & - \\
\hline$E_{A} P C_{E}$ & A & 40 & 30 & - & 30 \\
\hline$E_{B} P C_{E}$ & B & 40 & 30 & - & 30 \\
\hline $\mathrm{E}_{\mathrm{C}} P \mathrm{C}_{\mathrm{E}}$ & C & 40 & 30 & - & 30 \\
\hline $\mathbf{P}$ & - & - & 100 & - & - \\
\hline $\mathbf{P}_{\mathbf{P}}$ & - & - & - & 100 & - \\
\hline$C_{E}$ & - & - & - & - & 100 \\
\hline$E_{D}$ & Comercial & 100 & - & - & - \\
\hline
\end{tabular}

$E_{A} P P_{P}=$ eucalipto $A$ + pergamino + película plateada. $E_{B} P P_{P}=$ eucalipto $B$ + pergamino+película plateada. $E_{C} P P_{P}=$ eucaliptoC+pergamino+película plateada. $E_{A} P_{E}=$ EucaliptoA + pergamino + cascaexterna. $E_{B} P C_{E}=$ eucaliptoB + pergamino + cascaexterna. $E_{C} P C_{E}=$ EucaliptoC + pergamino + casca externa. $\mathrm{P}=$ pergamino. $\mathrm{P}_{\mathrm{P}}=$ película plateada. $\mathrm{C}_{\mathrm{E}}=$ casca externa. $\mathrm{E}_{\mathrm{D}}=$ pellets comercial.

$$
D B m P=\frac{V_{1}\left(\frac{D B_{0 \%}+D B_{25 \%}}{2}\right)+V_{2}\left(\frac{D B_{25 \%}+D B_{50 \%}}{2}\right)+V_{3}\left(\frac{D B_{50 \%}+D B_{75 \%}}{2}\right)+V_{4}\left(\frac{D B_{75 \%}+D B_{100 \%}}{2}\right)}{\sum_{i=1}^{n} V_{i}}
$$

en que:

DBmP: densidad básica media ponderada $\left(\mathrm{g} \mathrm{cm}^{-3}\right)$.

DBm: densidad básica las posiciones longitudinales del árbol $\left(\mathrm{g} \mathrm{cm}^{-3}\right)$.

$\mathrm{V}_{1}$ a $\mathrm{V}_{4}$ : volumen de las secciones entre las posiciones 0 y $25 ; 25$ y $50 ; 50$ y $75 ; 75$ y $100 \%$ de la altura comercial $\left(\mathrm{m}^{3}\right)$.

La relación de lignina sigingil:guayacil fue realizada en duplicado mediante el método de thioacidolyses, al utilizar tetracosano padrón interno (5 mg de tetracosano $\left(\mathrm{C}_{24}\right) / \mathrm{mL} \mathrm{de} \mathrm{CH}_{2} \mathrm{Cl}_{2}$ ), por medio de cromatografía gaseosa (CG) de acuerdo con el método descrito por Robinson y Mansfield (2009).

\section{PRODUCCIÓN Y EVALUACIÓN DE LOS PELLETS}

En la producción de los pellets fueron utilizadas las composiciones de la Tabla 2. Los pellets fueron producidos en una prensa peletizadora de laboratorio con una matriz circular horizontal. El equipo posee una capacidad de producción de $110 \mathrm{k} \mathrm{h}^{-1}$, con una matriz plana de $6,0 \mathrm{~mm}$, la temperatura de la peletizadora durante la producción de los pellets varió aproximadamente entre $80-95^{\circ} \mathrm{C}$ y la presión de compactación es de $300 \mathrm{kgf} \mathrm{cm}^{-2}$. EEl material de los clones utilizado poseía una granulometría de $3 \mathrm{~mm}$ y humedad de 12\%. Además de los pellets producidos en el laboratorio, también fue evaluada una muestra comercial nacional $\left(\mathrm{E}_{\mathrm{D}}\right)$ producida con madera $100 \%$ de eucalipto, que fue utilizada como un parámetro de comparación, ya que no fue posible peletizar cada clon (A, B y C) al 100\%, debido a las especificaciones del equipo.

Tabla 2. Caracterización de los clones de Eucalyptus

Tabela 2. Caracterização dos clones de Eucalyptus

\begin{tabular}{ccccc}
\hline Clon & DBmP & S:G & EXT & LT \\
\hline A & 0,530 & 3,32 & 2,05 & 30,20 \\
B & 0,530 & 2,96 & 2,34 & 30,14 \\
C & 0,550 & 2,83 & 2,90 & 31,44
\end{tabular}

$\mathrm{DBmP}=$ densidad básica media ponderada $\left(\mathrm{g} \mathrm{cm}^{-3}\right) . \mathrm{S}: \mathrm{G}$ = lignina siringil:guayacil. EXT = extractivos en acetona (\%). LT = lignina total (\%).

La humedad de los pellets se llevó a cabo a través de la metodología descrita por la norma DIN EN 14774-1 (DIN, 2010a), el contenido de cenizas se determinó de acuerdo con la norma DIN EN 14775 (DIN, 2009) y el contenido de extractivo en acetona fue determinado por medio la norma TAPPI T204 (TAPPI, 1997).

Para la obtención del poder calorífico superior (PCS) fue utilizado un calorímetro digital marca IKA C-200 de acuerdo con los procedimientos descritos en la norma ASTM E711-87 (ASTM, 2004). El poder calorífico inferior (PCI), base seca fue estimado mediante la ecuación 2. El poder calorífico líquido fue estimado mediante la siguiente ecuación 3. 
Pegoretti et al. - Colorimetría de pellets de eucalipto y residuos de la

cafeicultura y sus relaciones con los parámetros de calidad

en que

PCI es el poder calorífico inferior ( $\left.\mathrm{kcal} \mathrm{kg}^{-1}\right)$

PCS es el poder calorífico superior ( $\left.\mathrm{kcal} \mathrm{kg}^{-1}\right) \mathrm{e}$

$\mathrm{H}$ es la contenido de hidrogeno (\% en base seca)

$$
P C L=P C I x\left[\left(\frac{100-H u b u}{100}\right)\right]-(6 \times H u b u)
$$

En que

PCL es el poder calorífico líquido ( $\mathrm{kcal} \mathrm{kg}^{-1}$ )

PCI es el poder calorífico inferior ( $\left.\mathrm{kcal} \mathrm{kg}^{-1}\right)$

Hubu es el humedad (base húmeda)

Para el análisis de color de los pellets, se utilizó la metodología del sistema CIE- $L^{*} a^{*} b^{*}$ (CIE, 1976). El color fue determinado con el auxilio de un espectrofotómetro portátil, realizando la lectura de 15 pellets escogidos aleatoriamente, con características buenas, es decir, pellets bien plastificados y sin grietas, para cada tratamiento a lo largo de la cara radial-longitudinal de cada pellets, para lo cual se obtuvieron los valores de las coordenadas L* (claridad o luminosidad), a* (matices del eje rojo-verde) y b* (matices del eje amarillo-azul) para cada pellet.

El diámetro de abertura utilizado para el área de iluminación del equipo fue de $3 \mathrm{~mm}$ (SAV - Small Area View). Se utilizó la "luminosidad padrón D65, ángulo de observación de $10^{\circ}$ y luz especular incluida. Para las lecturas, el equipo fue calibrado con el padrón negro y blanco, y para la calibración del padrón blanco, se utilizó una placa de calibración del propio equipo.

Las tres coordenadas de color de los pellets fueron comparadas con la muestra control (pellets comercial) y luego fueron calculadas las variaciones de cada coordenada, siendo ellas: $\Delta \mathrm{L}^{*}, \Delta \mathrm{a}^{*}$ y $\Delta \mathrm{b}^{*}$. La variación total de los colores de los pellets fue determinada utilizando la ecuación 4, de acuerdo con Konica Minolta (1998).

$$
\Delta E^{*}=\sqrt{\left(\Delta L^{*}\right)^{2}+\left(\Delta a^{*}\right)^{2}+\left(\Delta b^{*}\right)^{2}}
$$

en que

$\Delta \mathrm{E}^{*}$ : variación total de color de los pellets.

$\Delta \mathrm{L}^{*}, \Delta \mathrm{a}^{*} \mathrm{y} \Delta \mathrm{b}^{*}$ : variación de las coordenadas $\mathrm{L}^{*}, \mathrm{a}^{*} \mathrm{y} \mathrm{b}^{*}$ respectivamente.

\section{RESULTADOS Y DISCUSIÓN}

De acuerdo a las informaciones de los clones utilizados (Tabla 2), se puede constatar que el clon C posee mayor densidad y mayor porcentaje de lignina total y de extractivos, comparado con los clones A y B, también el mayor porcentaje de extractivos. Estas biomasas de Eucalyptus evaluadas presentaron alto porcentaje de lignina, lo cual constatado por Protásio et al. (2017), va contribuir para una mejor performance mecánica de los pellets producidos.

El mayor porcentaje de extractivos entre todas las biomasas evaluadas fue para la película plateada $\left(\mathrm{P}_{\mathrm{p}}\right)$ con $7,77 \%$ (Tabla 3), el cual es un parámetro que influencia positivamente el poder calorífico de la biomasa lignocelulósica (TELMO; LOUSADA, 2011). Por lo tanto, se observó una tendencia donde los mayores porcentajes de extractivos están asociados con pellets más oscuros y con menor luminosidad (Tablas 3 y 4); siendo esta una característica cualitativa indeseable para la comercialización de este biocombustible sólido. Respecto al porcentaje de cenizas, los mayores valores fueron para los pellets de $\left(\mathrm{P}_{\mathrm{P}}\right)$ y $\left(\mathrm{C}_{\mathrm{E}}\right)$, pero aun así están dentro de los rangos de las normas europeas. Por lo tanto, altos valores de este parámetro son indeseables en los procesos industriales y en el uso doméstico (calefacción de residencias), ya que reduce el poder calorífico del combustible y reduce la vida útil de los equipos.

Obernberger y Thek (2010), resaltan que el contenido de cenizas de la materia-prima no influencia el proceso de peletización cuando el porcentaje es menor que 3,0\% para maderas y 10,0\% para biomasas agrícolas, aspecto que fue evidenciado en este estudio. En ese sentido una de las grandes ventajas en el uso de mezclas de biomasas es que ayuda a aumentar el porcentaje de cenizas en los pellets (SCATOLINO et al., 2018). También ayuda aumentar la durabilidad que es un factor importante en la logística y consumo de los pellets. 
Tabla 3. Valores medios de contenidos de humedad, extractivo, cenizas y poder calorífico de los pellets

Tabela 3. Valores médios de teor de umidade, extrativos, cinzas e poder calorífico dos pellets

\begin{tabular}{|c|c|c|c|c|c|}
\hline \multirow[t]{2}{*}{ Pellets } & \multirow{2}{*}{$\begin{array}{l}\text { Humedad }_{\mathrm{bu}} \\
(\%)\end{array}$} & \multirow{2}{*}{$\begin{array}{l}\text { Extractivos } \\
\text { Totales (\%) }\end{array}$} & \multirow{2}{*}{$\begin{array}{c}\text { Cenizas } \\
(\%)\end{array}$} & \multicolumn{2}{|c|}{$\begin{array}{l}\text { Poder calorífico } \\
\text { (MJ kg-1) }\end{array}$} \\
\hline & & & & Líquido & Superior \\
\hline$E_{A} P P_{P}$ & $9,71 \mathrm{a}^{(0,395)}$ & $4,63 b^{(0,001)}$ & $4,70 d^{(0,130)}$ & $16,74 \mathrm{a}^{(0,032)}$ & $19,97 \mathrm{a}^{(0,035)}$ \\
\hline $\mathrm{E}_{\mathrm{B}} \mathrm{PP}_{\mathrm{P}}$ & $9,78 \mathrm{a}^{(0,296)}$ & $4,33 b^{(0,063)}$ & $4,00 e^{(0,107)}$ & $17,08 \mathrm{a}^{(0,139)}$ & $20,34 a^{(0,153)}$ \\
\hline $\mathrm{E}_{\mathrm{C}} \mathrm{PP}_{\mathrm{P}}$ & $9,84 \mathrm{a}^{(0,063)}$ & $4,72 b^{(0,388)}$ & $3,57 f^{(0,097)}$ & $16,57 b^{(0,168)}$ & $19,45 b^{(0,186)}$ \\
\hline $\mathrm{E}_{\mathrm{A}} \mathrm{PC}_{\mathrm{E}}$ & $9,24 \mathrm{a}^{(0,007)}$ & $1,88 e^{(0,084)}$ & $4,17 \mathrm{e}^{(0,069)}$ & $16,64 \mathrm{a}^{(0,038)}$ & $19,86 \mathrm{a}^{(0,044)}$ \\
\hline $\mathrm{E}_{\mathrm{B}} \mathrm{PC}_{\mathrm{E}}$ & $8,88 b^{(0,070)}$ & $1,86 \mathrm{e}^{(0,190)}$ & $6,28 c^{(0,169)}$ & $16,51 b^{(0,210)}$ & $19,60 b^{(0,230)}$ \\
\hline $\mathrm{E}_{\mathrm{C}} \mathrm{PC}_{\mathrm{E}}$ & $8,35 b^{(0,381)}$ & $2,64 d^{(0,509)}$ & $7,01 b^{(0,182)}$ & $16,84 \mathrm{a}^{(0,150)}$ & $20,08 a^{(0,165)}$ \\
\hline$P$ & $8,64 b^{(0,183)}$ & $1,69 e^{(0,205)}$ & $2,55 \mathrm{~g}^{(0,025)}$ & $16,96 \mathrm{a}^{(0,085)}$ & $20,21 a^{(0,094)}$ \\
\hline$P_{P}$ & $8,84 b^{(0,205)}$ & $7,77 \mathrm{a}^{(0,176)}$ & $9,90 \mathrm{a}^{(0,034)}$ & $16,26 b^{(0,044)}$ & $19,44 b^{(0,050)}$ \\
\hline $\mathrm{C}_{\mathrm{E}}$ & $9,50 \mathrm{a}^{(0,261)}$ & $2,85 d^{(0,120)}$ & $9,69 \mathrm{a}^{(0,030)}$ & $15,76 \mathrm{c}^{(0,192)}$ & $18,89 c^{(0,213}$ \\
\hline$E_{D}$ & $7,98 b^{(0,650)}$ & $3,41 \mathrm{c}^{(0,035)}$ & $1,28 h^{(0,021)}$ & $16,51 b^{(0,235)}$ & $19,71 b^{(0,260)}$ \\
\hline
\end{tabular}

$E_{A} P P_{P}=$ eucaliptoA+pergamino + película plateada. $E_{B} P P_{P}=$ eucaliptoB + pergamino +película plateada. $E_{C} P P_{P}=$ eucaliptoC + pergamino + película plateada. $E_{A} P_{E_{E}}=$ EucaliptoA + pergamino + cascaexterna. $E_{B} P_{E}=$ eucaliptoB + pergamino + cascaexterna. $E_{C} P_{E}=$ EucaliptoC + pergamino + casca externa. $P=$ pergamino. $P_{P}=$ película plateada. $C_{E}=$ casca externa. $E_{D}=$ pellets comercial. Medias seguidas de la misma letra no difieren entre sí al 5\% de probabilidad, por el test Scott Knott. (---) Desviación estándar.

Tabla 4. Valores de las coordenadas colorimétricas y alteraciones de los pellets de cada muestra en relación a la control Tabela 4. Valores das coordenadas colorimétricas e alterações dos pellets de cada amostra em relação ao controle

\begin{tabular}{|c|c|c|c|c|c|c|c|}
\hline Pellets & $L^{*}$ & $\Delta \mathbf{L}^{*}$ & $a^{*}$ & $\Delta \mathbf{a}^{*}$ & $\mathbf{b}^{*}$ & $\Delta \mathbf{b}^{*}$ & $\Delta \mathrm{E}^{*}$ \\
\hline $\mathrm{E}_{\mathrm{D}}$ & $58,69 \mathrm{a}^{(2,864)}$ & --- & $7,72 a^{(0,847)}$ & --- & $17,91 b^{(1,066)}$ & --- & --- \\
\hline $\mathrm{E}_{\mathrm{A}} \mathrm{PP}_{\mathrm{P}}$ & $44,32 \mathrm{c}^{(2,660)}$ & $-14,37$ & $7,32 b^{(0,772)}$ & $-0,40$ & $16,59 c^{(1,890)}$ & $-1,33$ & $14,63 c^{(4,443)}$ \\
\hline $\mathrm{E}_{\mathrm{B}} \mathrm{PP}_{\mathrm{P}}$ & $51,68 b^{(3,349)}$ & $-7,00$ & $8,08 a^{(0,996)}$ & 0,36 & $22,42 a^{(1,543)}$ & 4,51 & $9,22 d^{(3,536)}$ \\
\hline $\mathrm{E}_{\mathrm{C}} \mathrm{PP}_{\mathrm{P}}$ & $42,44 \mathrm{~d}^{(2,659)}$ & $-16,24$ & $7,37 b^{(0,302)}$ & $-0,35$ & $15,86 c^{(1,585)}$ & $-2,05$ & $16,53 c^{(4,697)}$ \\
\hline$E_{A} P C_{E}$ & $41,75 d^{(1,925)}$ & $-16,93$ & $7,16 b^{(0,392)}$ & $-0,56$ & $14,90 \mathrm{~d}^{(1,080)}$ & $-3,01$ & $17,29 \mathrm{c}^{(4,044)}$ \\
\hline$E_{B} P C_{E}$ & $44,83 c^{(3,460)}$ & $-13,86$ & $7,13 b^{(0,570)}$ & $-0,59$ & $14,56 \mathrm{~d}^{(1,381)}$ & $-3,36$ & $14,40 \mathrm{c}^{(4,322)}$ \\
\hline$E_{C} P C_{E}$ & $43,69 \mathrm{c}^{(2,626)}$ & $-15,00$ & $7,21 \mathrm{~b}^{(0,540)}$ & $-0,51$ & $14,11 \mathrm{~d}^{(1,273)}$ & $-3,80$ & $15,59 \mathrm{c}^{(3,884)}$ \\
\hline$P$ & $67,83 \mathrm{e}^{(2,468)}$ & $-20,86$ & $6,50 \mathrm{c}^{(1,058)}$ & $-1,22$ & $10,97 \mathrm{e}^{(2,305)}$ & $-6,94$ & $22,08 b^{(5,068)}$ \\
\hline$P_{P}$ & $30,87 f^{(1,286)}$ & $-27,82$ & $2,19 \mathrm{e}^{(0,368)}$ & $-5,53$ & $5,19 f^{(1,364)}$ & $-12,73$ & $31,14 a^{(3,448)}$ \\
\hline$C_{E}$ & $32,00 f^{(1,090)}$ & $-26,69$ & $4,58 \mathrm{~d}^{(0,712)}$ & $-3,14$ & $6,26 f^{(1,318)}$ & $-11,66$ & $29,34 a^{(3,080)}$ \\
\hline
\end{tabular}

$\mathrm{E}_{\mathrm{A}} \mathrm{PP}_{\mathrm{P}}=$ eucaliptoA+pergamino + película plateada. $\mathrm{E}_{\mathrm{B}} \mathrm{PP}_{\mathrm{P}}=$ eucaliptoB + pergamino + película plateada. $\mathrm{E}_{\mathrm{C}} \mathrm{PP}_{\mathrm{P}}=$ eucaliptoC + pergamino + película plateada. $E_{A} P C_{E}=$ Eucalipto $A$ + pergamino + cascaexterna. $E_{B} P C_{E}=$ eucaliptoB + pergamino + cascaexterna. $E_{C} P C_{E}=$ EucaliptoC + pergamino + casca externa. $P=$ pergamino. $P_{P}=$ película plateada. $C_{E}=$ casca externa. $E_{D}=$ pellets comercial. $L *$ (luminosidad), $a^{*}$ (coordenada del eje rojo-verde), $\mathrm{b}^{*}$ (coordenada del eje azul-amarillo), $\Delta \mathrm{E}$ *ab - termo: variación total de color después del peletizado. Medias seguidas de la misma letra no difieren entre sí a 5\% de probabilidad, por el test Scott Knott. (---) Desviación estándar.

Por otra parte, para verificar la existencia de diferencias en los colores entre los pellets, fueron calculados los valores de variación de color $(\Delta \mathrm{E})$. Todos los pellets (Tabla 4) tuvieron una variación de $\Delta \mathrm{E}$ de 9,22 a 31,14, por lo tanto, se consideran perceptibles al ojo humano, pues las diferencias de color para $\Delta \mathrm{E}$ se puede percibir claramente en valores superiores a 3 (DIRCKX et al., 1992).

Se encontró que los valores de $\Delta \mathrm{E}$ están altamente correlacionados con los contenidos de cenizas, lo que demuestra que altas concentraciones de cenizas tendrán una relación con pellets más oscuros, como fue el caso de los pellets de $\left(\mathrm{P}_{\mathrm{P}}\right)$ y $\left(\mathrm{C}_{\mathrm{F}}\right)$ con un $\Delta \mathrm{E}$ de 31,14 y 29,34, respectivamente (Tabla 4).

En la Figura 1, están agrupados los pellets de acuerdo con el grado de luminosidad. Los pellets identificados con el color verde poseen alto contenido de cenizas y humedad, siendo agrupados cerca de cero, lo que significa que son los más oscuros con base a la escala del sistema. Las composiciones de eucalipto-pergamino-película plateada $\left(\mathrm{EPP}_{\mathrm{p}}\right)$ y eucalipto-pergamino-casca externa $\left(\mathrm{EPC}_{\mathrm{E}}\right)$ están clasificados con valores medios de 44,78 de luminosidad ( $\left.\mathrm{L}^{*}\right)$. Los pellets más claros fueron los de pergamino $(\mathrm{P})$, con valores medios de 37,83 de $\mathrm{L}^{*}$, y los mayores contenidos de cenizas fueron para los pellets de $\left(\mathrm{P}_{\mathrm{P}}\right)$ y $\left(\mathrm{C}_{\mathrm{E}}\right)$, con valores medios de 9,90 y 9,69, respectivamente, clasificados por el sistema como los más oscuros, ya que se sitúan más cercanos de cero (Figura 1). Por otro lado, no se encontró una correlación estadísticamente importante entre humedad y luminosidad (Figura 2). Posiblemente, esto ocurrió debido a la homogenización de las biomasas lignocelulósicas para la fabricación de los pellets. 


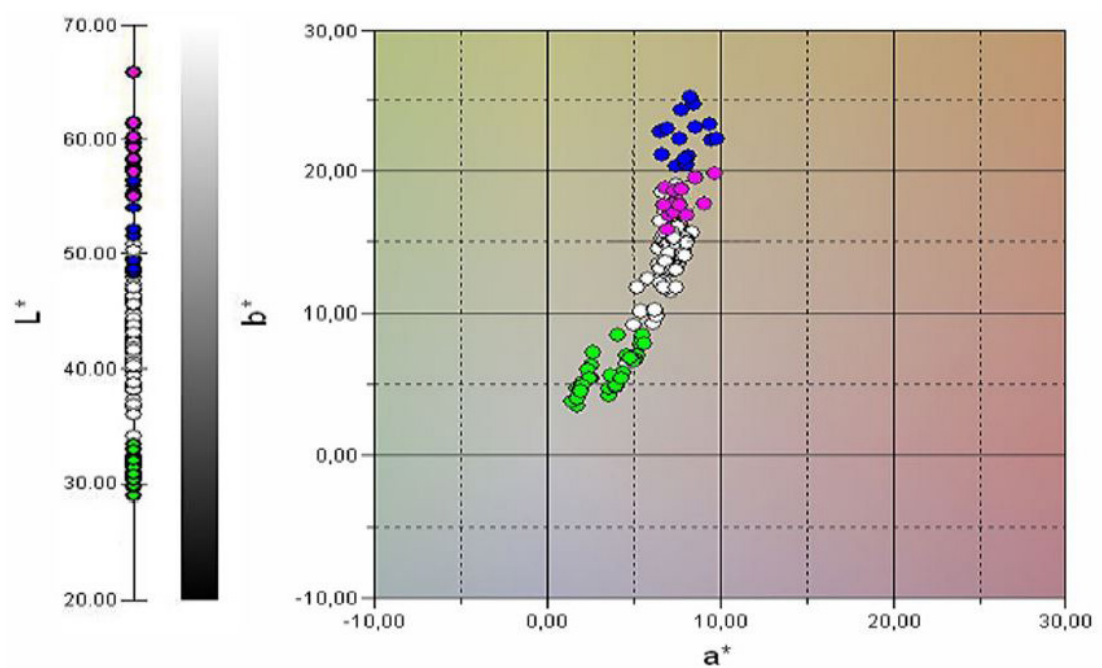

OPellets de pergamino (P). OPellets del clon comercial $\left(E_{D}\right)$. OPellets de las mezclas $\left(E_{P P}-E_{P} C_{E}\right)$. OPellets de película plateada $\left(P_{P}\right)$ y Pellets casca externa $\left(\mathrm{C}_{\mathrm{E}}\right)$.

Figura 1. Clasificación de los pellets de acuerdo con los parámetros colorimétricos.

Figura 1. Classificação dos pellets de acordo com os parâmetros colorimétricos.

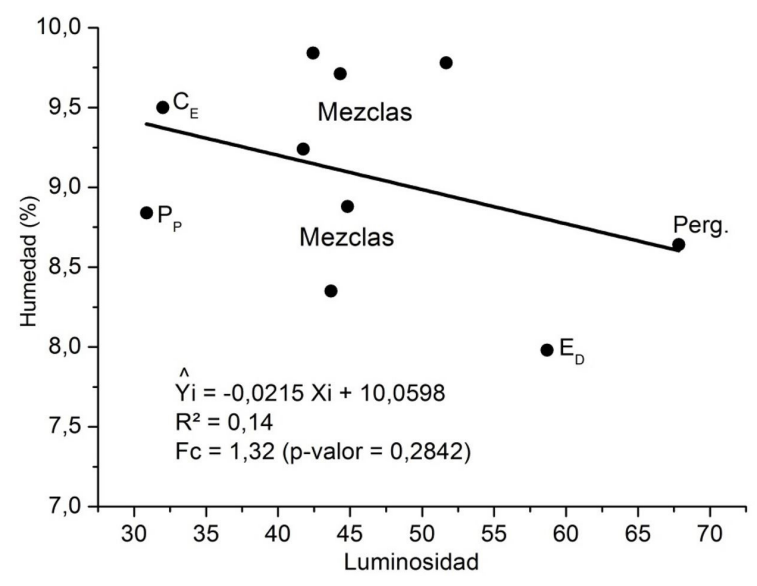

Figura 2. Relación que tiene la humedad respecto a la luminosidad de los pellets.

Figura 2. Relação entre a umidade e a luminosidade dos pellets.

Varios factores afectan las características y la calidad de los pellets, tales como: humedad, materia-prima y el modo como fue compactado el biocombustible. Los pellets pueden variar de color, ocurriendo que pueden ser unos más oscuros que otros. Sin embargo, esa variación no necesariamente debe ser vinculada a los componentes de la materia-prima. La temperatura utilizada en el momento de la peletización generalmente altera el color del pellet para más oscuro y con menor brillo, altos valores de luminosidad $\left(\mathrm{L}^{*}\right)$ y diferente higroscopicidad (LAM et al., 2011). Esto ocurre debido al contacto de los rodillos de la matriz y de la fricción durante la extrusión, que ocasiona el mayor oscurecimiento en la parte externa que en el interior del pellet.

Por lo tanto, el procedimiento de colorimetría es más confiable cuando los pellets son producidos con la misma temperatura, ya que facilita detectar las diferencias de color. Sin embargo, la capacidad del consumidor para poder definir la calidad de los pellets por medio el color todavía genera mucha incertidumbre.

Los mejores pellets son aquellos capaces de ser sometidos a esfuerzos mecánicos y liberar toda la energía cuando son quemados. Para eso, los pellets deben tener una baja humedad, densidades altas y altos valores energéticos. Por otro lado, se deben evitar las cenizas ya que ellas reducen el contenido energético de los pellets y pueden afectar negativamente su combustión. De acuerdo con Sgarbossa et al. (2014), la correlación entre el color por el sistema CIE-L*a*b* y los valores de contenido de cenizas es considerada un indicador apropiado, ya que existe una mayor preocupación entre los consumidores finales que utilizan el producto para la calefacción doméstica. Los mismos autores afirman que altos contenidos de cenizas influencian el color de los pellets. 
Los resultados obtenidos en este estudio son similares a los de Sgarbossa et al. (2014), quienes evaluaron los padrones colorimétricos de pellets de madera relacionados con la calidad y los parámetros energéticos. Pellets que poseen mayores porcentajes de cenizas son más oscuros y consecuentemente presentan menor poder calorífico y menor luminosidad (Figuras 3 y 4 ).
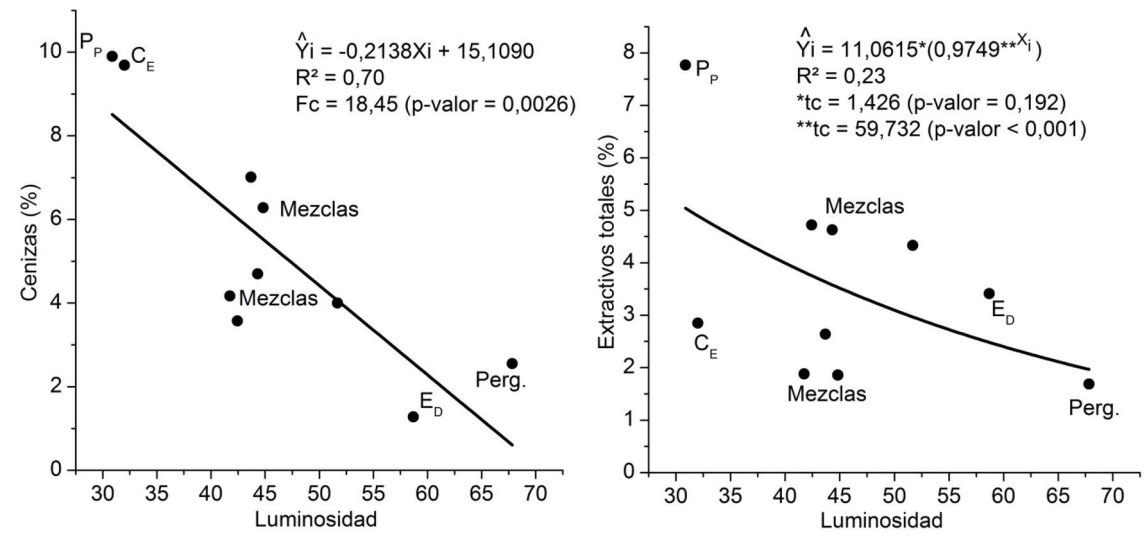

Figura 3. Relación entre el contenido de cenizas y extractivos totales respecto a la luminosidad de los pellets.

Figura 3. Relação entre os teores de cinzas e extrativos totais respeito a luminosidade dos pellets.
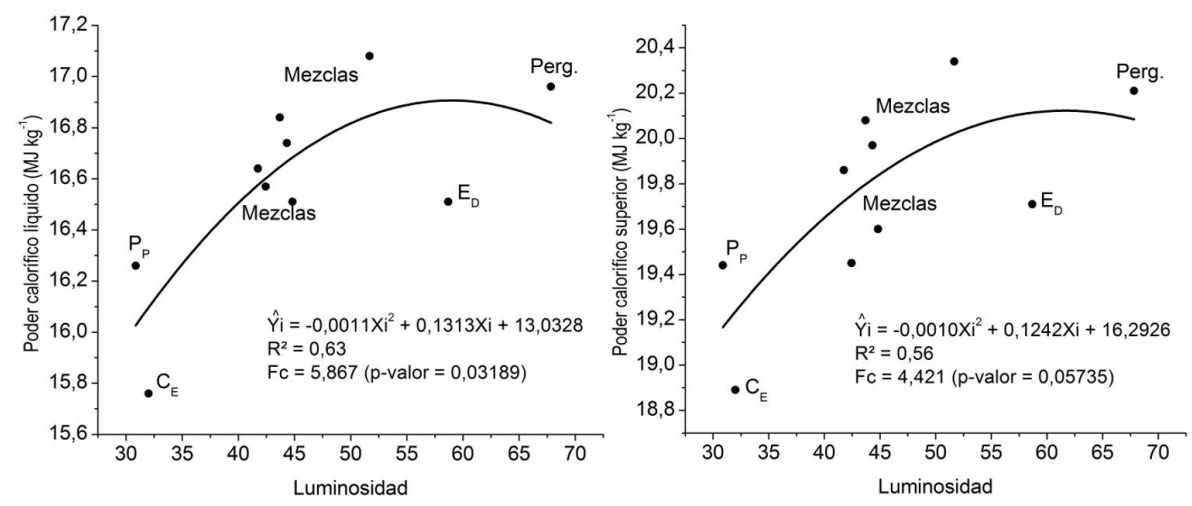

Figura 4. Relación entre poder calorífico líquido y superior respecto a la luminosidad de los pellets. Figura 4. Relação entre os poderes caloríficos líquido e superior com a luminosidade dos pellets.

Por esta razón, existe la tendencia de consumir pellets más claros por el hecho de que poseen menores cantidades de cenizas, las cuales son consideradas como indeseables en el uso de ese combustible granulado. Otra razón para usar el método de colorimetría, es que Brasil viene creciendo en el área energética debido a la instalación de plantas productoras de pellets (GARCIA; CARASCHI; VENTORIM, 2017a), las cuales en su mayoría están enfocadas en la producción del producto con fines de exportación principalmente a Europa, ya que el valor máximo de este parámetro no puede exceder el $0.70 \%$ (pellets tipo A) de acuerdo a la norma DIN EN 14961-2 (DIN, 2010b) y para pellets no madereros, mezclas o de residuos agrícolas no puede superar el 5\% de acuerdo a la norma DIN EN 14961-6 (DIN, 2012).

En vista de esto, la producción de pellets más claros y ajustados a las normas europeas se ha convertido en una condición para entrar a este sector del mercado. En este orden, se constató que el contenido de cenizas influenció el color de los pellets y disminuye el poder energético del material (Figuras 3 y 4). Además que las muestras de $\left(\mathrm{C}_{\mathrm{E}}\right)$ y $\left(\mathrm{P}_{\mathrm{P}}\right)$ poseen los mayores contenidos de cenizas, siendo catalogados como los más oscuros, y los pellets comerciales de madera de eucalipto ( $\left.\mathrm{E}_{\mathrm{D}}\right)$ poseen el menor contenido de cenizas, siendo así los más claros junto con los pellets de pergamino (P). Por lo tanto, es posible afirmar que pellets más oscuros contienen altos contenidos de cenizas y baja luminosidad, convirtiéndolos en un producto no deseado en la producción de este tipo de biocombustible.

De igual manera, se vio una correlación muy baja en el porcentaje de extractivos en relación con la luminosidad. Ya que influencian las propiedades físicas y energéticas (VARGAS-MORENO et al., 2012), 
Pegoretti et al. - Colorimetría de pellets de eucalipto y residuos de la

cafeicultura y sus relaciones con los parámetros de calidad

y dependiendo de su estabilidad térmica y el porcentaje de esas sustancias pueden contribuir al aumento de la coloración en los pellets.

Por lo tanto, un alto contenido de extractivos influencia el color de los pellets, que puede perjudicar su aspecto visual al consumidor, el cual está acostumbrado a consumir pellets más claros (pino) y a veces deja de consumir pellets más oscuros (eucalipto o mezclas de biomasa) solo por la apariencia, pellets posean la misma calidad. Por otro lado, debemos tener en cuenta que mayores contenidos de extractivos pueden facilitar la inflamabilidad de la biomasa en temperaturas más bajas, esto en efecto de su mayor volatilidad y como consecuencia va a acelerar el inicio del proceso de combustión (GUO et al. 2010; POLETTO, 2016).

Finalmente, se determinó que la colorimetría es un método que puede ser aplicado a los pellets de forma rápida, además de ser de bajo costo para poder estimar la cantidad de cenizas y extractivos presentes en los pellets. Así observamos cómo estos parámetros influyen el color de este. Sin embargo, cabe destacar que todavía este método no es normalizado, pero debido a su fácil aplicación y su importancia, es un método que puede convertirse en un parámetro de calidad a ser utilizado cada vez más en lo que respecta a la producción de los pellets.

Se sugiere llevar a cabo más ensayos con diferentes especies y en diferentes temperaturas, para así tener más conocimientos sobre este sistema que puede ser muy útil, sencillo y de bajo costo a la hora de verificar la calidad de los pellets.

\section{CONCLUSIONES}

Fue encontrado un alto grado de correlación entre las características colorimétricas (CIE-L*a*b*) de los pellets con fines energéticos y los valores del contenido de cenizas, que han sido considerados como un buen indicador de calidad, ya que existe una preocupación entre los consumidores finales por su uso en estufas domésticas.

Las correlaciones confirman que los pellets más oscuros y con menor luminosidad son propensos a tener mayor contenido de cenizas y menor poder calorífico.

También fue determinado que el porcentaje de extractivos influencian el color de los pellets. Lo cual, el bajo porcentaje de extractivo está relacionado con una alta luminosidad, consecuentemente, un bajo porcentaje de cenizas.

Por lo tanto, la hipótesis del estudio es aceptada, el sistema CIE-L*a* b* sirve como herramienta para verificar la calidad de los pellets, principalmente, de acuerdo con el contenido de cenizas y menor poder calorífico.

\section{REFERENCIAS BIBLIOGRÁFICAS}

AMORIM, P. G. R.; GONÇALEZ, J. C.; CAMARGOS, J. A. A. Propriedades da madeira de Pinus caribaea e Eucalyptus grandis estimadas por colorimetria. Cerne, Lavras, v. 19, n. 3, p. 461-466, 2013.

ASTM - AMERICAN SOCIETY FOR TESTING MATERIALS. ASTM E711-87: Standard Test Method for Gross Calorific Value of Refuse-Derived Fuel by the Bomb Calorimeter.Philadelphia, 2004. 8 p.

ABNT - ASSOCIAÇÃO BRASILEIRA DE NORMAS TÉCNICAS - ABNT. NBR 11941: madeira - determinação da densidade básica. Rio de Janeiro, 2003. 6 p.

ABNT - ASSOCIAÇÃO BRASILEIRA DE NORMAS TÉCNICAS. NBR 6230: métodos de ensaio para madeiras. Rio de Janeiro, 1985.89 p.

BRASIL. CONSELHO NACIONAL DO MEIO AMBIENTE (CONAMA). Resolução no 436, de 22 de dezembro de 2011. Brasília, 2011. Disponível em: < http://www2.mma.gov.br/port/conama/legiabre.cfm?codlegi=660 >. Acesso em: 10 ago 2015.

CIE - Commission Internationale de l'Éclairage. Colorimetry. Part 4: Vienna, 1986.

CUBERO-ABARCA, R.; MOYA, R.; VALARET, J.; TOMAZELLO FILHO, M. Use of coffee (Coffea arabica) pulp for the production of briquettes and pellets for heat generation. Ciência e Agrotecnologia, Lavras, v. 38, n. 5, p. 461-470, 2014. 
DIN - DEUTSCHES INSTITUT FÜR NORMUNG. DIN EN 14775: Determination of ash content. Berlim, 2009. $12 \mathrm{p}$.

DIN - DEUTSCHES INSTITUT FÜR NORMUNG. DIN EN 14774-1: Determination of moisture content - Oven dry method - Part 1: Total moisture - Reference method. Berlim, 2010a. 10 p.

DIN - DEUTSCHES INSTITUT FÜR NORMUNG. DIN EN 14961-2: Solid biofuels - Fuel specifications and classes - Part 2: Wood pellets for non-industrial use. Berlim, 2010b. 15 p.

DIN - DEUTSCHES INSTITUT FÜR NORMUNG, DIN EN 14961-6: Solid biofuels - Fuel specifications and classes - Part 6: Non-woody pellets for non-industrial use. Berlim, 2012. 16 p.

DIRCKX, O.; TRIBOULOT-TROUY, MC; MERLIN, A.; DEGLIESE, X. Modifications de la couleur du bois d'Abies grandis exposé à la lumière solaire. Annals of Forest Science, Les Ulis, v. 49, n. 5, p. 425-447,1992.

FARIA, W.; PROTÁSIO, T.; TRUGILHO, P.; PEREIRA, B.; CARNEIRO, A.; ANDRADE, C.; JUNIOR, J. Transformação dos resíduos lignocelulósicos da cafeicultura em pellets para geração de energia térmica. Coffee Science, Lavras, v. 11, n. 1, p. 137 - 147, 2016.

GARCIA, D. P.; CARASCHI, J. C.; VENTORIM, G.; VIEIRA, F. H. A.; PROTÁSIO, T. P. Comparative energy properties of torrefied pellets in relation to pine and elephant grass pellets. BioResources, Raleigh, v. 13, n. 2, p. 2898-2906, 2018.

GARCIA, D.; CARASCHI, J.; VENTORIM, G. O setor de pellets no Brasil. Ciência da Madeira, Pelotas, v. 8, n. 1, p. 21-28, 2017a.

GARCIA, D. P.; CARASCHI, J. C.; VENTORIM, G. Emissões de gases do efeito estufa da queima de pellets de madeira. Floresta, Curitiba, v. 47, n. 3, p. 297 - 306, 2017b.

GARCIA, D.; CARASCHI, J.; VENTORIM, G.; VIEIRA, F. Trends and challenges of brazilian pellets industry originated from agroforestry. Cerne, Lavras, v. 22, n. 3, p. 233 - 240, 2016.

GARCÍA, R.; PIZARRO, C.; LAVÍN, A.; BUENO, J. Biomass proximate analysis using thermogravimetry. Bioresource Technology, Essex, v.139, p. 1-4, 2013.

GUO, X.; WANG, S.; WANG, K.; LIU, Q.; LUO, Z. Influence of extractives on mechanism of biomass pyrolysis. Journal of Fuel Chemistry and Technology, Taiyuan, v. 38, n. 1, p. 42-46, 2010.

KONICA MINOLTA SENSING Inc. Comunicação precisa da cor: controle de qualidade da percepção à instrumentação. São Paulo: Konica, 1998. 59 p.

LAÉRCIO, C.; MULLER, M.; JÚNIOR, A.; CONDE, L. Produção de pellets de madeira - o caso da Bio-Energy no Espírito Santo. Biomassa \& Energia, Viçosa, v. 1, n. 1, p. 45-52, 2004.

LAM, P.; SOKHANSANJ, S.; Bi X; Lim CJ.; MELIN, S. Energy input and quality of pellets made from steamexploded Douglas Fir (Pseudotsuga menziesii). Energy \& Fuels, Washington, v. 25, n. 4, p. 1521 - 1528, 2011.

LEITE, E. R. S.; PROTÁSIO, T. P.; ROSADO, S. C. S.; TRUGILHO, P. F.; NAPOLI, A. Estudo tecnológico da madeira de Coffea arabica l. visando à combustão completa e pirólise. Coffee Science, Lavras, v. 10, n. 2, p. $158-168,2015$

MOYA, R.; BERROCAL, A. Wood colour variation in sapwood and heartwood of young trees of Tectona grandis and its relationship with plantation characteristics, site, and decay resistance. Annals of Forest Science, Paris, v. 67, n. 1, p. 109 - 109, 2010.

OBERnBERGER, I.; THEK, G. The pellet handbook: The production and thermal utilization of pellets. London: Earthscan, p.593, 2010.

OLIVEIRA, C. M. Pellets: Pequenos Notáveis. Biomais, Curitiba, v. 2, n. 10, p. 22-32, 2015.

POLETTO, M. Effect of extractive content on the thermal stability of two wood species from Brazil. Maderas. Ciencia y tecnología, Concepción, v. 18, n. 3, p. 435 - 442, 2016. 
Pegoretti et al. - Colorimetría de pellets de eucalipto y residuos de la

cafeicultura y sus relaciones con los parámetros de calidad

Protásio, T. P.; TRugilho, P. F.; ARAúJO, A. C. C.; BASTOS, T. A.; ROSADO, S. C. S.; PINTO, J. F. N. Classificação de clones de Eucalyptus por meio da relação siringil/guaiacil e das características de crescimento para uso energético. Scientia Forestalis, Piracicaba, v.45, n. 114, p.327-341, 2017.

ROBINSON, A. R.; MANSFIELD, S. D. Rapid analysis of poplar lignin monomer composition by a streamlined thioacidolysis procedure and near-infrared reflectance-based prediction modeling. The Plant Journal, Hoboken, v. 58, n.4, p. 706-706, 2009.

SGARBOSSA, A.; COSTA, C.; MENESATTI, P.; ANTONUCCI, F.; PALLOTTINO, F.; ZANETTI, M.; GRIGOLATO, S.; CAVALLIA, R. Colorimetric patterns of wood pellets and their relations with quality and energy parameters. Fuel, London, v. 137, n. 1, p. $70-76,2014$.

SCATOLINO, V. M.; CABRAL NETO, F. L.; PROTÁSIO, T. P.; CARNEIRO, A. C. O.; ANDRADE, C. R.; GUIMARÃES JÚNIOR, J. B.; MENDES, M. L. Options for generation of sustainable energy: production of pellets based on combinations between lignocellulosic biomasses. Waste and Biomass Valorization, Dordrecht, v. 9, n. 3, p. 479-489.

TAPPI - TECHNICAL ASSOCIATION OF THE PULP AND PAPER INDUSTRY. T 204 cm-97: Solvent extractives of wood and pulp. Atlanta, 1997. 4 p.

TUMULURU, J. S.; WRIGHT, C. T.; HESS, J. R.; KENNEY, K. L. A review of biomass densification systems to develop uniform feedstock commodities for bioenergy application. Biofuels, Bioproducts and Biorefining, Hoboken, v. 5, n. 6, p. 683-707, 2011.

TELMO, C.; LOUSADA, J. Heating values of wood pellets from different species. Biomass and Bioenergy, Oxford, v.35, n.7, p. 2634-2639, 2011.

VARGAS-MORENO, J. M.; CALLEJÓN-FERRE, A. J.; PÉREZALONSO, J.; VELÁZQUEZ-MARTÍ, B. A review of the mathematical models for predicting the heating value of biomass materials. Renewable and Sustainable Energy Reviews, Amsterdam, v. 16, n. 5, p. 3065-3083, 2012.

ZANUNCIO, A. J. V.; MOTTA, J. P.; SILVEIRA, T. A.; FARIAS, E. S.; TRUGILHO, P. F. Physical and colorimetric changes in Eucalyptus grandis wood after heat treatment. Bioresources, Raleigh, v. 9, n.1, p. 293-302, 2014.

Recebido em: 29/12/2017

Aceito em: 26/07/2018 